\title{
Cementing the relationship between conventional and advanced semen parameters
}

Bashir M. Ayad ${ }^{1,2^{*}} \mathbb{D}$, Ibukun P. Oyeyipo ${ }^{2,3}$, Gerhard Van der Horst ${ }^{2}$ and Stefan S. Du Plessis ${ }^{2,4}$

\begin{abstract}
Background: Affordable conventional semen analysis remains a fundamental procedure to be performed routinely during the diagnosis of male infertility. Advanced semen analyses provide valuable clinical insights in treatmentrelated decision-making, but these are highly expensive and lack universal standardization. This study aimed at determining the relationship between conventional semen parameters, measured with assistance of computer-aided sperm analysis (CASA), and a set of advanced semen tests. Basic semen analysis $(n=124)$ was performed according to the World Health Organization (WHO) guidelines. Sperm DNA fragmentation and intracellular superoxide $\left(\mathrm{O}_{2}^{-*}\right)$ levels were assessed by flow cytometry. Seminal plasma thiobarbituric acid reactive substances (TBARS) levels as well as superoxide dismutase (SOD) and catalase (CAT) activity were measured by spectrophotometry. Spearman's rank correlation coefficient was used, with significance set at $p<0.05$.

Results: Semen $\mathrm{pH}$ correlated negatively with TBARS $(p<0.01)$. The proportions of total and progressively motile as well as rapid spermatozoa correlated positively with CAT activity $(p<0.05)$. Sperm viability correlated negatively with both $\mathrm{O}_{2}^{-\cdot}(p<0.05)$ and DNA fragmentation $(p=0.01)$, while normal morphology correlated negatively with $\mathrm{O}_{2}^{-} \cdot$ levels $(p<0.05)$ and positively with CAT activity $(p<0.05)$. Straight-line velocity $(\mathrm{VCL})$ and average-path velocity (VAP) correlated negatively with both $\mathrm{O}_{2}^{-\cdot}(p<0.01)$ and TBARS $(p<0.01)$. Amplitude of lateral head displacement (ALH) correlated negatively with $\mathrm{O}_{2}^{-\cdot}(p<0.01)$ and DNA fragmentation $(p<0.01)$, while its correlation with SOD activity was positive $(p<0.05)$.

Conclusion: The results obtained from this study support the validity of some CASA parameters as sensitive indicators of changes in sperm oxidative status and DNA integrity. Predicting advanced from conventional parameters through the building of linear regression models should be considered for future studies.
\end{abstract}

Keywords: CASA, DNA fragmentation, Semen analysis, Sperm motility, Oxidative stress

\section{Background}

In addition to a detailed medical history and a thorough physical examination, conventional semen analysis remains a fundamental procedure performed on routine basis during the diagnosis of male infertility [1]. Being cost-effective and not technically demanding, semen

\footnotetext{
*Correspondence: ayadbm74@gmail.com

${ }^{1}$ Department of Physiology, Faculty of Medicine, Misurata University,

Misurata, Libya

Full list of author information is available at the end of the article
}

analysis is largely used as a preliminary diagnostic tool for the evaluation of male infertility [2]. The analysis provides essential information about the basic characteristics of semen, including the volume, sperm concentration, motility, and viability and morphology. However, conventional semen analysis, if performed manually, is criticized for being subjective, time consuming, and prone to inter- and intra-laboratory variations [3]. The potential counting and interpretation errors associated with the subjective visual assessment of the traditional semen analysis have highlighted the absolute necessity 
for computerized systems designed to automate the analysis [4]. Indeed, computer-aided sperm analysis (CASA), if used proficiently under identical settings, is undeniably a powerful approach for the objective assessment of spermatozoa $[5,6]$.

The World Health Organization (WHO) laboratory manuals for the examination and processing of human semen provide a primary reference guideline for standardizing semen analysis [7]. Most of the traditional and automated semen analysis methods have aligned their measurements according to these criteria [8]. The inclusion of normal reference values of semen parameters in the WHO manuals has been beneficial in establishing some consistency regarding the basic characteristics of the normal ejaculate [9]. However, semen parameter values do not necessarily reflect the functional integrity of spermatozoa, and studies have revealed a significant overlap in the semen characteristics between fertile and infertile men [10]. Consequently, a large proportion of men with normal semen analysis results are often diagnosed with unexplained infertility as the underlying pathophysiology of sperm functional deficiencies remains largely unknown [2]. The recent substantial progress toward understanding the mechanisms regulating sperm function has driven the development of a variety of assays for proper evaluation of the functional quality of spermatozoa. These assays provide valuable clinical insights into multiple aspects of sperm function, including DNA integrity as well as oxidative stress and membrane lipid peroxidation. This information can assist the clinician to a great extent in treatment-related decisionmaking [4]. However, in most cases, these assays are primarily used for research purposes and are not considered part of the routine assessment of male infertility. This is mainly attributed to the complexity and lack of universal standardization in addition to the high costs of these assays, which adds a further financial burden to a couple undergoing fertility investigations [11].

Several studies have investigated the relationship between conventional and advanced semen quality markers; however, results have often been found inconsistent. For instance, some studies have revealed that increased reactive oxygen species (ROS) production was negatively correlated with impaired sperm concentration, motility, morphology, and viability [12-14]. Other studies, however, failed to demonstrate any significant association between ROS levels and these parameters $[15,16]$.

Therefore, there is a need to develop a model that can indicate the extent to which changes in each individual measurement of the conventional semen analysis, predominantly measured by CASA, are related to changes in the advanced parameters. This study aimed at establishing statistical correlations between conventional semen parameters obtained with CASA and a set of advanced sperm/semen variables. This will allow for exploring the extent to which changes in each individual measurement of the conventional semen analysis are related to changes in other advanced semen parameters. This could also assist in reducing the necessity for advanced sperm function testing, representing cost-effective measures of the overall semen quality for some men undergoing infertility assessment.

\section{Methods \\ Study design}

Ethical approval for the study was granted from the Health Research Ethics Committee of the Faculty of Medicine and Health Sciences at Stellenbosch University $(\mathrm{S} 15 / 02 / 045)$. Semen samples were obtained from 124 donors between 20 and 30 years of age, participating in the sperm donor program at the Stellenbosch University Reproductive Research Group. Informed written consent was obtained from all donors and the study was conducted in accordance with the Declaration of Helsinki [17]. All samples were collected by masturbation in a private room adjacent to the laboratory and assessed according to the WHO guidelines [7]. Due to sample volume and technical limitations, not all procedures were performed on each individual sample. Consequently, 40 samples were used for the analysis of superoxide $\left(\mathrm{O}_{2}{ }^{-\cdot}\right)$, another 40 samples were used for the assessment of DNA fragmentation, while 44 samples were used for thiobarbituric acid reactive substances (TBARS), catalase (CAT), and superoxide dismutase (SOD) analyses.

\section{Semen analysis}

After liquefaction, semen volume and $\mathrm{pH}$ were measured. Samples were analyzed for sperm concentration, motility, and kinematic parameters using CASA (Sperm Class Analyzer version 5.4-SCA ${ }^{\circledR}$, Microptic, S.L., Barcelona, Spain,) equipped with a Basler A312fc digital color camera (Microptic, S.L., Barcelona, Spain). The assessed CASA parameters include sperm concentration, total sperm count (TSC), curvilinear velocity (VCL), straight line velocity (VSL), average path velocity (VAP), linearity (LIN), straightness (STR), Wobble (WOB), amplitude of lateral head displacement (ALH), and beat cross frequency (BCF).

The percentage of viable spermatozoa was determined by a dye-exclusion technique using Eosin-Nigrosin stain (Sigma-Aldrich, St Louis, MO, USA). From each slide, 100 spermatozoa were counted by means of the counter module of the SCA ${ }^{\circledR}$ morphology system.

Sperm morphology was assessed from smears fixed and stained with SpermBlue (SpermBlue ${ }^{\circledR}$, Microptic, S.L., Barcelona, Spain), following the manufacturer's 
guidelines [18]. Stained spermatozoa were evaluated by computer-aided sperm morphology analysis (CASMA) using the $\mathrm{SCA}^{\circledR}$ morphology module. The $\mathrm{SCA}^{\circledR}$ settings were adjusted as described by Maree et al. [19].

\section{Assessment of advanced semen parameters}

Sperm DNA fragmentation was assessed by using terminal deoxynucleotidyl transferase-mediated deoxyuridine triphosphate (dUTP) nick end-labeling (TUNEL) assay with an APO-DIRECT ${ }^{\mathrm{TM}}$ kit (BD Biosciences Pharmingen, San Diego, CA, USA) according to the protocol described by Sharma et al. [20]. Results are represented as percentage of DNA-fragmented spermatozoa.

Intracellular $\mathrm{O}_{2}^{-\cdot}$ production was measured with dihydroethidium (DHE) as probe, as previously described [21]. Data were reported as median DHE fluorescence intensity (MFI).

Seminal plasma levels of TBARS were determined, as described by Jentzsch et al. [22]. Spectrophotometric methods with a SPECTRA-max PLUS-384 spectrophotometer and SoftMax ${ }^{\circledR}$ Pro 4.8 software (Molecular Devices Corporation, Labotec Industrial Technologies, Cape Town, South Africa) were utilized for data acquisition and analysis. Results were expressed as $\mu \mathrm{mol} / \mathrm{L}$ using molar extinction coefficient of $1.54 \times 10^{5} / \mathrm{M} / \mathrm{cm}$ at 532 nm.
CAT activity in seminal plasma was assessed according to the method described by Aebi [23]. The $\mathrm{H}_{2} \mathrm{O}_{2}$ decomposition rate was determined spectrophotometrically at $240 \mathrm{~nm}$ (SPECTRAmaxPLUS-384, Molecular Devices, San Francisco, CA, USA). Values were reported as units/ $\mathrm{mL}(\mathrm{U} / \mathrm{mL})$.

For the assessment of SOD activity in seminal plasma, the SOD Assay Kit-WST (Sigma-Aldrich, St. Louis, MO, USA) was utilized according to the manufacturer's instructions. The absorbance was read on a microplate reader at $450 \mathrm{~nm}$. Results were reported as units $/ \mathrm{mg}$ protein $(\mathrm{U} / \mathrm{mg}$ protein).

\section{Statistical analysis}

For the determination of correlation between conventional and advanced semen parameters, Spearman's rank correlation coefficient $(r)$ test was used. Statistical analysis was performed using the DellTM StatisticaTM data analysis software system, version 13 (StatSoft Inc.). Statistical significance was set at $p<0.05$.

\section{Results}

As can be seen from Tables 1 and 2, the means of the basic semen parameters (volume, $\mathrm{pH}$, concentration, total sperm count (T.S.C.), viability, morphology, motility, progressive motility) exceeded the lower reference limits of the WHO.

Table 1 Correlation analysis between basic and advanced semen parameters

\begin{tabular}{|c|c|c|c|c|c|c|}
\hline & & $\mathrm{O}_{2}^{-\cdot}(\mathrm{MFI})$ & TBARS ( $\mu \mathrm{mol} / \mathrm{L})$ & CAT (U/mL) & SOD (U/mg) & DNA fragmented (\%) \\
\hline & Mean \pm SEM & $155.3 \pm 16.82$ & $24.25 \pm 2.63$ & $36.16 \pm 1.5$ & $4.09 \pm 0.22$ & $12.76 \pm 0.8$ \\
\hline \multirow[t]{3}{*}{ Volume (mL) } & $r$ & -0.05 & 0.03 & -0.05 & -0.15 & 0.14 \\
\hline & $p$ & 0.75 & 0.83 & 0.76 & 0.32 & 0.39 \\
\hline & Mean \pm SEM & $2.89 \pm 0.21$ & $2.68 \pm 0.21$ & $2.68 \pm 0.21$ & $68 \pm 0.21$ & $2.61 \pm 0.21$ \\
\hline \multirow[t]{3}{*}{$\mathrm{pH}$} & $r$ & -0.13 & -0.47 & -0.11 & 0.29 & -0.03 \\
\hline & $p$ & 0.43 & $<0.01$ & 0.48 & 0.06 & 0.84 \\
\hline & Mean \pm SEM & $7.62 \pm 0.03$ & $7.67 \pm 0.03$ & $7.67 \pm 0.03$ & $7.67 \pm 0.03$ & $7.7 \pm 0.03$ \\
\hline \multirow[t]{3}{*}{ Concentration $\left(10^{6} / \mathrm{mL}\right)$} & r & 0.10 & -0.16 & 0.03 & 0.17 & -0.24 \\
\hline & $p$ & 0.55 & 0.31 & 0.84 & 0.27 & 0.13 \\
\hline & Mean \pm SEM & $66.3 \pm 6.51$ & $45.7 \pm 3.64$ & $45.7 \pm 3.64$ & $45.7 \pm 3.64$ & $46.81 \pm 3.08$ \\
\hline \multirow[t]{3}{*}{ T.S.C. (10\%/ejaculate) } & r & -0.01 & -0.02 & -0.02 & -0.16 & 0.03 \\
\hline & $p$ & 0.97 & 0.92 & 0.87 & 0.30 & 0.87 \\
\hline & Mean \pm SEM & $197.2 \pm 28.54$ & $123.0 \pm 14.7$ & $123.0 \pm 14.7$ & $123.0 \pm 14.7$ & $123.6 \pm 14.10$ \\
\hline \multirow[t]{3}{*}{ Viability (\%) } & r & -0.33 & 0.02 & 0.01 & 0.03 & -0.43 \\
\hline & $p$ & 0.04 & 0.91 & 0.95 & 0.86 & 0.01 \\
\hline & Mean \pm SEM & $68.79 \pm 1.34$ & $67.5 \pm 1.43$ & $67.5 \pm 1.43$ & $67.5 \pm 1.43$ & $67.53 \pm 1.3$ \\
\hline \multirow[t]{3}{*}{ Normal morphology (\%) } & r & -0.39 & -0.10 & 0.33 & 0.23 & 0.08 \\
\hline & $p$ & 0.02 & 0.57 & 0.04 & 0.17 & 0.65 \\
\hline & Mean \pm SEM & $16.39 \pm 1.16$ & $18.45 \pm 1.06$ & $18.45 \pm 1.06$ & $18.45 \pm 1.06$ & $17.5 \pm 1.03$ \\
\hline
\end{tabular}

$\mathrm{O}_{2}^{-\cdot}$ superoxide anion, $\mathrm{MFI}$ Median DHE fluorescence intensity, TBARS Thiobarbituric acid reactive substances, CAT Catalase, SOD Superoxide dismutase, T.S.C. Total sperm count 
Table 2 Correlation analysis between sperm motility/velocity characteristics and advanced semen parameters

\begin{tabular}{|c|c|c|c|c|c|c|}
\hline & Mean \pm SEM & $\begin{array}{l}\mathrm{O}_{2}^{-\cdot}(\mathrm{MFI}) \\
155.3 \pm 16.82\end{array}$ & $\begin{array}{l}\text { TBARS }(\mu \mathrm{mol} / \mathrm{L}) \\
24.25 \pm 2.63\end{array}$ & $\begin{array}{l}\text { CAT }(\mathrm{U} / \mathrm{mL}) \\
36.16 \pm 1.5\end{array}$ & $\begin{array}{l}\text { SOD }(\mathrm{U} / \mathrm{mg}) \\
4.09 \pm 0.22\end{array}$ & $\begin{array}{l}\text { DNA fragmented (\%) } \\
12.76 \pm 0.8\end{array}$ \\
\hline \multirow[t]{3}{*}{ Motility (\%) } & $r$ & -0.27 & -0.09 & 0.33 & 0.05 & -0.21 \\
\hline & $p$ & 0.09 & 0.56 & 0.03 & 0.75 & 0.19 \\
\hline & Mean \pm SEM & $65.4 \pm 2.71$ & $61.6 \pm 1.94$ & $61.6 \pm 1.94$ & $61.6 \pm 1.94$ & $59.09 \pm 2.24$ \\
\hline \multirow[t]{3}{*}{ Progressive motility (\%) } & $r$ & -0.25 & -0.30 & 0.31 & 0.13 & -0.22 \\
\hline & $p$ & 0.12 & 0.05 & 0.04 & 0.41 & 0.17 \\
\hline & Mean \pm SEM & $52.0 \pm 2.6$ & $47.82 \pm 1.85$ & $47.82 \pm 1.85$ & $47.82 \pm 1.85$ & $45.67 \pm 2.02$ \\
\hline \multirow[t]{3}{*}{ Rapid (\%) } & r & -0.26 & -0.31 & 0.31 & 0.13 & -0.22 \\
\hline & $p$ & 0.10 & 0.04 & 0.04 & 0.39 & 0.17 \\
\hline & Mean \pm SEM & $51.15 \pm 2.63$ & $46.72 \pm 1.86$ & $46.72 \pm 1.86$ & $46.72 \pm 1.86$ & $44.52 \pm 2.03$ \\
\hline \multirow[t]{3}{*}{ Medium (\%) } & r & 0.11 & 0.51 & -0.15 & -0.24 & -0.03 \\
\hline & $p$ & 0.51 & $<0.01$ & 0.32 & 0.12 & 0.84 \\
\hline & Mean \pm SEM & $6.24 \pm 0.35$ & $6.6 \pm 0.33$ & $6.6 \pm 0.33$ & $6.6 \pm 0.33$ & $6.3 \pm 0.39$ \\
\hline \multirow[t]{3}{*}{ Slow (\%) } & r & 0.06 & 0.38 & -0.05 & -0.07 & 0.10 \\
\hline & $p$ & 0.72 & 0.01 & 0.73 & 0.67 & 0.54 \\
\hline & Mean \pm SEM & $8.0 \pm 0.35$ & $8.25 \pm 0.4$ & $8.25 \pm 0.4$ & $8.25 \pm 0.4$ & $8.22 \pm$ \\
\hline
\end{tabular}

$\mathrm{O}_{2}^{-\cdot}$ superoxide anion, MFI Median DHE fluorescence intensity, TBARS Thiobarbituric acid reactive substances, CAT Catalase, SOD Superoxide dismutase

Semen volume, T.S.C., and concentration did not correlate significantly with any of the advanced parameters. Semen $\mathrm{pH}$ only correlated significantly with seminal TBARS and showed a negative correlation. The percentage of viable spermatozoa correlated significantly and negatively with both intracellular $\mathrm{O}_{2}^{-\cdot}$ levels and sperm DNA fragmentation. The proportion of morphologically normal spermatozoa correlated significantly and negatively with the intracellular $\mathrm{O}_{2}^{-\cdot}$ levels, while its correlation with seminal plasma CAT activity was significant and positive (Table 1).

Table 2 displays a significant and positive correlation between seminal plasma CAT activity and the proportions of both total and progressively motile spermatozoa, whereas the correlation between these motility parameters and other advanced parameters was not significant. The proportion of rapid spermatozoa correlated significantly and negatively with seminal TBARS levels, and significantly and positively with CAT activity, though its correlation with other advanced parameters did not reach statistical significance. The proportions of medium and slow spermatozoa correlated significantly and positively with seminal TBARS levels, while their correlations with other advanced parameters were not significant.

As shown in Table 3, VCL correlated significantly and negatively with both intracellular $\mathrm{O}_{2}^{-\cdot}$ and seminal plasma TBARS levels, while its correlation with seminal SOD levels was significant and positive. VSL correlated significantly and negatively with the seminal TBARS levels and significantly and positively with the percentage of DNA fragmentation. VAP correlated significantly and negatively with both intracellular $\mathrm{O}_{2}^{-\bullet}$ and seminal plasma TBARS levels, whereas its correlation with other advanced parameters was not statistically significant. Both LIN and STR correlated significantly and positively with the proportion of DNA fragmented spermatozoa. ALH correlated significantly and negatively with both intracellular $\mathrm{O}_{2}^{-\cdot}$ and DNA fragmentation and significantly and positively with SOD activity, while the correlation between BCF and seminal plasma TBARS levels was significant and negative.

\section{Discussion}

This study effectively used multivariate analysis in establishing a statistical correlation between various conventional and advanced semen parameters, as summarized in Fig. 1.

\section{Sperm intracellular $\mathrm{O}_{2}^{-\cdot}$}

In conditions where the intracellular redox homeostasis is disturbed, ROS becomes highly reactive and instigates peroxidative damage, which adversely affects sperm quality [24]. In the current study, a significant and negative correlation was observed between the proportion of morphologically normal spermatozoa and intracellular $\mathrm{O}_{2}^{-}$ levels. These findings are consistent with previous studies also showing an inverse association between sperm morphology and ROS production [13, 25]. Furthermore, substantially higher levels of ROS were reported in teratozoospermic samples compared with normozoospermic controls [26]. The link between abnormal sperm morphology and ROS overproduction is generally attributed 
Table 3 Correlation analysis between sperm kinematics and advanced semen parameters

\begin{tabular}{|c|c|c|c|c|c|c|}
\hline & Mean \pm SEM & $\begin{array}{l}\mathrm{O}_{2}^{-\cdot}(\mathrm{MFI}) \\
155.3 \pm 16.82\end{array}$ & $\begin{array}{l}\text { TBARS }(\mu \mathrm{mol} / \mathrm{L}) \\
24.25 \pm 2.63\end{array}$ & $\begin{array}{l}\text { CAT }(\mathrm{U} / \mathrm{mL}) \\
36.16 \pm 1.5\end{array}$ & $\begin{array}{l}\mathrm{SOD}(\mathrm{U} / \mathrm{mg}) \\
4.09 \pm 0.22\end{array}$ & $\begin{array}{l}\text { DNA fragmented (\%) } \\
12.76 \pm 0.8\end{array}$ \\
\hline \multirow[t]{3}{*}{$\operatorname{VCL}(\mu \mathrm{m} / \mathrm{s})$} & $r$ & -0.46 & -0.62 & 0.14 & 0.35 & -0.09 \\
\hline & $p$ & $<0.01$ & $<0.01$ & 0.36 & 0.02 & 0.60 \\
\hline & Mean \pm SEM & $83.33 \pm 2.35$ & $77.9 \pm 1.82$ & $77.9 \pm 1.82$ & $77.9 \pm 1.82$ & $77.05 \pm 2.0$ \\
\hline \multirow[t]{3}{*}{ VSL $(\mu \mathrm{m} / \mathrm{s})$} & $r$ & -0.18 & -0.33 & 0.00 & -0.10 & 0.36 \\
\hline & $p$ & 0.26 & 0.03 & 0.99 & 0.51 & 0.02 \\
\hline & Mean \pm SEM & $32.53 \pm 1.04$ & $30.73 \pm 0.7$ & $30.73 \pm 0.7$ & $30.73 \pm 0.7$ & $30.75 \pm 0.81$ \\
\hline \multirow[t]{3}{*}{$\operatorname{VAP}(\mu \mathrm{m} / \mathrm{s})$} & $r$ & -0.43 & -0.60 & 0.06 & 0.25 & 0.15 \\
\hline & $p$ & $<0.01$ & $<0.01$ & 0.71 & 0.11 & 0.36 \\
\hline & Mean \pm SEM & $53.15 \pm 1.3$ & $51.74 \pm 0.9$ & $51.74 \pm 0.9$ & $51.74 \pm 0.9$ & $51.4 \pm 1.0$ \\
\hline \multirow[t]{3}{*}{ LIN (\%) } & $r$ & 0.24 & 0.01 & -0.11 & -0.30 & 0.48 \\
\hline & $p$ & 0.14 & 0.97 & 0.46 & 0.05 & $<0.01$ \\
\hline & Mean \pm SEM & $39.52 \pm 1.12$ & $40.03 \pm 1.0$ & $40.03 \pm 1.0$ & $40.03 \pm 1.0$ & $40.5 \pm 1.13$ \\
\hline \multirow[t]{3}{*}{ STR (\%) } & $r$ & 0.14 & 0.03 & 0.01 & -0.25 & 0.43 \\
\hline & $p$ & 0.38 & 0.83 & 0.97 & 0.10 & $<0.01$ \\
\hline & Mean \pm SEM & $61.29 \pm 1.3$ & $59.6 \pm 1.04$ & $59.6 \pm 1.04$ & $59.6 \pm 1.04$ & $60.1 \pm 1.21$ \\
\hline \multirow[t]{3}{*}{ ALH $(\mu \mathrm{m})$} & $r$ & -0.49 & -0.18 & 0.09 & 0.33 & -0.42 \\
\hline & $p$ & $<0.01$ & 0.25 & 0.56 & 0.03 & $<0.01$ \\
\hline & Mean \pm SEM & $2.1 \pm 0.07$ & $1.9 \pm 0.04$ & $1.9 \pm 0.04$ & $1.9 \pm 0.04$ & $1.85 \pm 0.04$ \\
\hline \multirow[t]{3}{*}{$\mathrm{BCF}(\mathrm{Hz})$} & $r$ & -0.03 & -0.56 & 0.26 & 0.16 & 0.20 \\
\hline & $p$ & 0.84 & $<0.01$ & 0.09 & 0.30 & 0.22 \\
\hline & Mean \pm SEM & $14.7 \pm 0.4$ & $13.7 \pm 0.34$ & $13.7 \pm 0.34$ & $13.7 \pm 0.34$ & $13.71 \pm 0.38$ \\
\hline
\end{tabular}

$\mathrm{O}_{2}^{-\cdot}$ superoxide anion, MFI Median DHE fluorescence intensity, TBARS Thiobarbituric acid reactive substances, CAT Catalase, SOD Superoxide dismutase, VCL Straight line velocity, VSL Average path velocity, VAP Average path velocity, LIN Linearity, STR Straightness, ALH Lateral head displacement, BCF Beat cross frequency

to the presence of excess residual cytoplasm in the midpiece due to deficient cytoplasmic extrusion following spermiation [27]. Furthermore, nicotinamide adenine dinucleotide phosphate (NADPH) oxidase 5 (NOX5), a novel NADPH oxidase responsible for the generation of $\mathrm{O}_{2}^{-\cdot}$ in a calcium-dependant manner, has recently been reported to be positively correlated with the incidence of sperm abnormal morphology [26]. Abnormal spermatozoa are also believed to contribute considerably to ROS production [28]. By implication, the relationship between increased ROS levels and sperm morphological abnormality appears to be a vicious cycle indicating a causeand-effect relationship that warrants further studies.

Intracellular $\mathrm{O}_{2}^{-\cdot}$ levels were also negatively, although not significantly, correlated with the proportions of total motile, progressively motile, and rapidly motile spermatozoa. Similar findings have been revealed by Pasqualotto et al. [29]. However, several other studies have reported a significant correlation between elevated levels of seminal ROS and impaired motility [13, 30]. It is important to note that these studies have mainly focused on extracellular ROS in seminal plasma, while the sperm intracellular ROS has apparently been disregarded. Interestingly, exogenous ROS has been shown to cause more serious adverse effects on sperm quality compared to equivalent levels of endogenous sperm ROS [31].

A significant negative correlation was also observed between sperm intracellular $\mathrm{O}_{2}^{-\cdot}$ and the kinematics VCL, VAP, and ALH. This implies that increased levels of intracellular $\mathrm{O}_{2}^{-\cdot}$ could initiate alterations in sperm swimming patterns, after which sperm quality may further deteriorate. The VAP is considered an important indicator of the forward swimming speed of spermatozoa; it estimates the time-averaged velocity of the sperm head along its average trajectory [32]. The inverse relationship between sperm $\mathrm{O}_{2}{ }^{-\bullet}$ levels and VAP may demonstrate the possible role of this free radical in constraining the actual rate of sperm forward movement within the female reproductive tract.

Both VCL and ALH represent the characteristics of the sperm head movement, which depends on the pattern of the flagellar beating. Increased values of these parameters are generally identified to be characteristic signs of sperm hyperactivation at the site of fertilization [33]. At low concentrations, the role of $\mathrm{O}_{2}^{-\cdot}$ in the initiation of sperm hyperactivation has been recognized [34]. However, the strong negative correlation between $\mathrm{O}_{2}^{-\cdot}$ and these kinematic parameters suggests that overproduction 


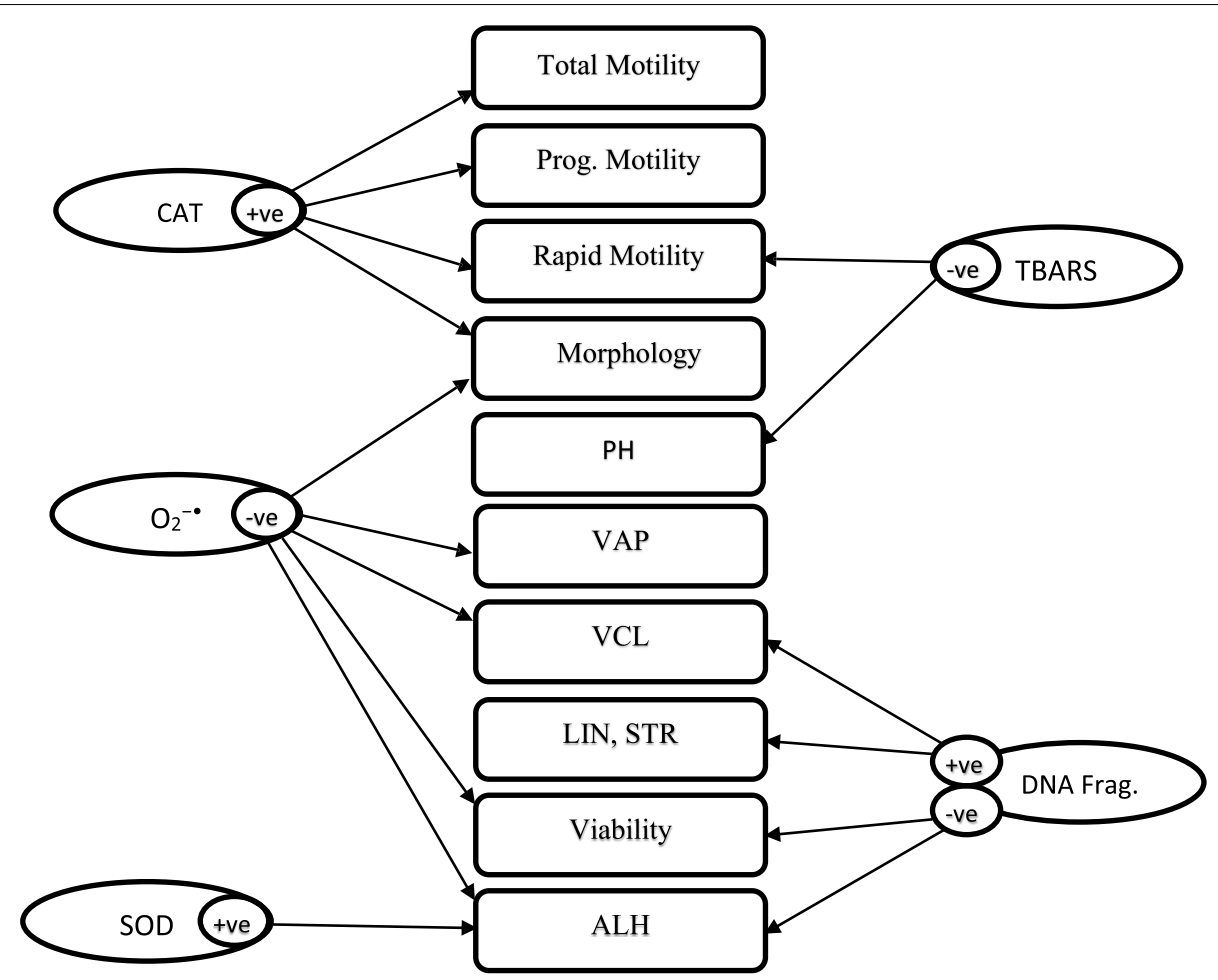

Fig. 1 Simplified schematic of the correlation between advanced and conventional semen parameters. $\mathrm{O}_{2}^{-*}$ (superoxide), TBARS (thiobarbituric acid reactive substances), SOD (superoxide dismutase), CAT (catalase), VCL (curvilinear velocity), VSL (straight-line velocity), VAP (average path velocity), LIN (linearity), STR (straightness), ALH (amplitude of lateral head displacement)

of intracellular $\mathrm{O}_{2}^{-\cdot}$ may contribute to decreased hyperactivated motility, which is critical to the success of fertilization. Further studies are needed to elucidate whether this is an actual cause and effect relationship or just a statistical correlation.

\section{TBARS}

The preservation of seminal plasma $\mathrm{pH}$ within its reference range (7.2-8.2) is essential for the regulation of various physiological functions of spermatozoa [35]. A significant negative correlation was found between TBARS levels and $\mathrm{pH}$ in semen. At physiological levels of $\mathrm{pH}$ in seminal plasma, malondialdehyde (MDA) which is a major end-product of lipid peroxidation is present as an enolate ion with low reactivity. However, lowering the $\mathrm{pH}$ causes the formation of highly reactive compound known as beta-hydroxyacrolein, which can react with other molecules in the vicinity and cause a considerable increase in lipid peroxidation [36].

Seminal plasma TBARS levels were significantly and negatively correlated with the proportion of rapidly motile spermatozoa. A similar, though nearly significant, trend was observed with regards to the proportions of progressive and total motility, whereas the correlation between TBARS levels and the proportions of medium and slow spermatozoa were significant and positive. The negative correlation between lipid peroxidation and sperm quality parameters of motility has been reported in several studies [37-39]. The sperm tail membrane is presumed to contain substantially higher amounts of total and individual biologically active unsaturated fatty acids [40], which contribute to its fluidity and flexibility critical to its movement, but simultaneously increase the tail membrane susceptibility to oxidative alterations. Therefore, rapid progressive motility is a sensitive parameter to lipid peroxidation that could be impaired prior to any detectable deterioration in other sperm motion characteristics.

This study also found a significant negative correlation between TBARS levels and the percentages of VCL, VSL, VAP, and BCF. Similar, but non-significant trends were observed with regard to the percentage of ALH. The parameters VCL, VSL, and VAP are measures of sperm progressive velocity and are revealed to play a vital role in sperm competition [41]. They have also been suggested as potential reliable indicators of male fertility $[42,43]$. $\mathrm{BCF}$ is one of the useful parameters which contribute substantially to the overall sperm linear progression. It indicates the rate at which the curvilinear path crosses the average path; however, it may vary in value depending 
on the VAP setting on the CASA instrument [6]. The sensitivity of these kinematic parameters to the deleterious effects of lipid peroxidation appears to be higher than that of the motility percentage, which was not correlated with TBARS levels in this study.

\section{Antioxidant enzyme activities}

Seminal plasma CAT activity was correlated significantly and positively with the proportions of total motile, progressively motile, rapidly motile, and morphologically normal spermatozoa, and significantly and negatively with the proportion of immotile spermatozoa. Similar but non-significant trends were observed for the SOD activity. These results are in agreement with those reported by Khosrowbeygi et al. [44]. Previous studies have further shown a substantially higher seminal plasma CAT activity in normozoospermic men as compared to men with asthenozoospermia [45-47] or asthenoteratozoospermia [44]. The observed positive correlations between CAT activity and sperm motility and normal morphology indicate the importance of this enzyme in the alleviation of ROS-induced oxidative damage, thereby reducing the cytotoxicity to spermatozoa.

On the other hand, available literature provides inconsistent results about the relationship between SOD activity and sperm quality. Some studies have revealed that increased SOD activity in seminal plasma is correlated with a significant improvement in the sperm overall motility [47-49]. Other studies have also reported similar but non-significant results $[44,50,51]$. The current study did not find a correlation between SOD activity in seminal plasma and sperm motility parameters, while the correlations with VCL and ALH were significantly positive. This suggests that elevated SOD activity in seminal plasma might be an indication of the development of spontaneous and premature hyperactivated motility of spermatozoa in the ejaculate. However, sperm regulation is a highly complex process involving multiple variables, thus, the specific role of SOD in the control of sperm motility remains poorly understood and necessitates further research.

\section{DNA fragmentation}

A significant negative correlation was also observed between the proportion of DNA fragmentation and sperm viability. This result is comparable with the previous findings from Brahem et al. [52]. Furthermore, an elevation in sperm DNA fragmentation induced by longterm in vitro incubation was reported to be accompanied by a substantial loss of sperm viability [53]. Similarly, a more recent study also demonstrated a strong negative correlation between sperm DNA fragmentation and viability in semen samples with DNA fragmentation rates $\geq$
$30 \%$ [54]. The current data presented confirms the observations of the abovementioned studies and suggests that sperm viability might represent a potential indicator and a cost-saving measure for semen quality.

The mechanism responsible for the incidence of DNA fragmentation in ejaculated human spermatozoa is not fully elucidated. One hypothesis proposes DNA breaks within ejaculated spermatozoa to be the result of apoptotic DNA cleavage during the early stages of spermatogenesis [55]. However, at the stage of DNA break down, apoptotic process is irreversible and the cells would be eliminated by Sertoli cells prior to ejaculation [56]. Another postulation points to the excessive exposure to ROS as being the causative agent for DNA fragmentation in ejaculated spermatozoa [57]. Sperm DNA fragmentation has previously been shown to correlate significantly and positively with the levels of ROS generated by spermatozoa [58]. Despite not being able to measure ROS and DNA fragmentation in the same samples, the current study showed a significant negative correlation between sperm intracellular $\mathrm{O}_{2}^{-\cdot}$ levels and the proportion of viable spermatozoa, thereby, indirectly implying a relationship between ROS and DNA fragmentation.

The current study observed a positive correlation between the sperm DNA fragmentation and the kinematic parameters: VCL, LIN, and STR. This shows that DNA-fragmented spermatozoa might still have the capacity for rapid forward motility. However, these spermatozoa might not be able to develop a state of hyperactivated motility at the site of fertilization as was indicated by the negative correlation observed in this study between the proportion of DNA fragmentation and ALH.

Several studies have been undertaken to investigate the possible correlation between sperm DNA fragmentation and a number of semen characteristics such as sperm concentration, motility, and morphology. Not all studies, however, have come to the same conclusions. Some studies have revealed poor correlations, as was observed in the present study, between the sperm DNA integrity and the conventional semen parameters of sperm concentration, motility, and morphology [59, 60]. In contrast, other studies have shown significant negative correlations between sperm DNA fragmentation and many of these semen variables [61, 62]. More recently, Boushaba and Belaaoui [63] reported negative correlations between sperm DNA fragmentation and sperm concentration as well as motility, while no significant correlation was found with regards to sperm morphology. As stated in a review by Evgeni et al. [64], the inconsistencies among different studies concerning the correlation between sperm DNA fragmentation and 
semen characteristics could be ascribed to several factors. These factors include dissimilarities in the assays used to quantify DNA fragmentation, the use of different techniques for the assessment of semen quality as well as variations in the characteristics of the populations across studies.

\section{Conclusion}

The correlations observed between conventional and advanced semen parameters enhance the applicability of conventional semen analysis as a more cost-effective and efficient approach for the diagnosis of idiopathic and unexplained male infertility. Indeed, various CASA motility and kinematic parameters have shown to be especially important indicators of sperm DNA fragmentation and oxidative stress markers. Continuing along these lines, the predicting of advanced from conventional parameters through the building of linear regression models should be considered for future studies. While further and larger studies are needed, the results obtained from this study substantiate the importance of CASA in bridging the gap between conventional and advanced semen parameters.

\begin{abstract}
Abbreviations
ALH: Lateral head displacement; BCF: Beat cross frequency; CASA: Computer-aided sperm analysis; CASMA: Computer-aided sperm morphology analysis; CAT: Catalase; DHE: Dihydroethidium; $\mathrm{H}_{2} \mathrm{O}_{2}$ : Hydrogen peroxide; LIN: Linearity; MFI: Median DHE fluorescence intensity; $\mathrm{O}_{2}^{--}$: Superoxide; ROS: Reactive oxygen species; SCA: Sperm class analyzer; SOD: Superoxide dismutase; STR: Straightness; TBARS: Thiobarbituric acid reactive substances; TSC: Total sperm count; TUNEL: Deoxynucleotidyl transferase dUTP nick end labeling; VAP: Average path velocity.
\end{abstract}

\section{Acknowledgements}

We would like to thank Professor Martin Kidd for assisting with statistical analysis.

\section{Authors' contributions \\ BMA designed the study, performed the measurements, analyzed the results, and drafted the manuscript; GvdH and IPO contributed to the study design and reviewed the final version of the manuscript; SSdP helped with the study design, supervised the experimental phase, col- laborated on the data analysis, interpreted the data, and assisted with the writing of the manuscript. The author(s) read and approved the final manuscript.}

\section{Funding}

None.

\section{Availability of data and materials}

All data generated or analyzed during this study are included in this published article.

\section{Declarations}

Ethics approval and consent to participate

Ethical approval for the study was granted from the Health Research Ethics Committee of the Faculty of Medicine and Health Sciences at Stellenbosch University (S15/02/045). Informed written consent was obtained from all donors and the study was conducted in accordance with the Declaration of Helsinki [17].

\section{Consent for publication}

Not applicable.

\section{Competing interests}

The authors declare that they have no competing interests.

\section{Author details}

${ }^{1}$ Department of Physiology, Faculty of Medicine, Misurata University, Misurata, Libya. ${ }^{2}$ Division of Medical Physiology, Faculty of Medicine and Health Sciences, Stellenbosch University, Tygerberg, South Africa. ${ }^{3}$ Department of Physiology, College of Health Sciences, Osun State University, Osogbo, Nigeria. ${ }^{4}$ Department of Basic Medical Sciences, Mohammed Bin Rashid University of Medicine and Health Sciences, Dubai, United Arab Emirates.

Received: 22 May 2021 Accepted: 10 October 2021

Published online: 19 October 2021

\section{References}

1. Jarow JP (2007) Diagnostic approach to the infertile male patient. Endocrinol Metab Clin North Am 36:297-311

2. Sikka SC, Hellstrom WJ (2016) Current updates on laboratory techniques for the diagnosis of male reproductive failure. Asian J Androl 18:392-401

3. Cooper TG, Yeung CH (2006) Computer-aided evaluation of assessment of "grade a" spermatozoa by experienced technicians. Fertil Steril 85:220-224

4. Van der Horst G, du Plessis SS (2017) Not just the marriage of Figaro: but the marriage of WHO/ESHRE semen analysis criteria with sperm functionality. Postępy Andrologii Online 4:6-21

5. Fréour T, Jean M, Mirallie S, Barriere P (2012) Computer-assisted sperm analysis parameters in young fertile sperm donors and relationship with age. Syst Biol Reprod Med 58:102-106

6. Lu JC, Huang YF, Lü NQ (2014) Computer-aided sperm analysis: past, present and future. Andrologia 46:329-338

7. World Health Organization (2010) WHO laboratory manual for the examination and processing of human semen, 5th edn. WHO: Press, Geneva

8. Mortimer ST, Van der Horst G, Mortimer D (2015) The future of computeraided sperm analysis. Asian J Androl 17:545-553

9. Björndahl L (2011) What is normal semen quality? On the use and abuse of reference limits for the interpretation of semen analysis results. Hum Fertil 14:179-186

10. Lewis SE (2007) Is sperm evaluation useful in predicting human fertility? Reproduction 134:31-40

11. Talwar P, Hayatnagarkar S (2015) Sperm function test. J Hum Reprod Sci 8:61-91

12. Zorn B, Vidmar G, Meden-Vrtovec H (2003) Seminal reactive oxygen species as predictors of fertilization, embryo quality and pregnancy rates after conventional in vitro fertilization and intracytoplasmic sperm injection. Int J Androl 26:279-285

13. Aziz N, Saleh RA, Sharma RK, Lewis-Jones I, Esfandiari N, Thomas AJ et al (2004) Novel association between sperm reactive oxygen species production, sperm morphological defects, and the sperm deformity index. Fertil Steril 81:349-354

14. Agarwal A, Sharma RK, Nallella KP, Thomas AJ, Alvarez JG, Sikka SC (2006) Reactive oxygen species as an independent marker of male factor infertility. Fert Steril. 86:878-885

15. Desai NR, Mahfouz R, Sharma R, Gupta S, Agarwal A (2010) Reactive oxygen species levels are independent of sperm concentration, motility, and abstinence in a normal, healthy, proven fertile man: a longitudinal study. Fert Steril 94:1541-1543

16. Homa ST, Vessey W, Perez-Miranda A, Riyait T, Agarwal A (2015) Reactive oxygen species (ROS) in human semen: determination of a reference range. J Assist Reprod Genet 32:757-764

17. World Medical Association Declaration of Helsinki (2013) Ethical principles for medical research involving human subjects. JAMA 310:2191-2194 
18. Van der Horst $G$, Maree $L$ (2010) SpermBlue ${ }^{\circledR}$ : a new universal stain for human and animal sperm which is also amenable to automated sperm morphology analysis. Biotech Histochem 84:299-308

19. Maree L, Du Plessis SS, Menkveld R, Van der Horst G (2010) Morphometric dimensions of the human sperm head depend on the staining method used. Hum Reprod 25:1369-1382

20. Sharma R, Masaki J, Agarwal A (2013) Sperm DNA fragmentation analysis using the TUNEL assay. In: Carrell DT, Aston K (eds) Spermatogenesis: Methods and Protocols ed. Human Press, New York, pp 121-136

21. Goss D, Oyeyipo IP, Skosana BT, Ayad BM, du Plessis SS (2016) Ameliorative potentials of quercetin against cotinine-induced toxic effects on human spermatozoa. APJR 5:193-197

22. Jentzsch AM, Bachmann H, Fürst P, Biesalski HK (1996) Improved analysis of malondialdehyde in human body fluids. Free Radic Biol Med 20:251-256

23. Aebi H (1974) Catalase in: Methods in enzymatic Analysis. Acadamic Press, pp 674-684

24. Du Plessis SS, Agarwal A, Halabi J, Tvrda E (2015) Contemporary evidence on the physiological role of reactive oxygen species in human sperm function. J Assist Reprod Genet 32:509-520

25. Agarwal A, Mulgund A, Sharma R, Sabanegh E (2014) Mechanisms of oligozoospermia: an oxidative stress perspective. Syst Biol Reprod Med 60:206-216

26. Agarwal A, Virk G, Ong C, du Plessis SS (2014) Effect of oxidative stress on male reproduction. World J Mens Health 32:1-17

27. Aitken RJ (1997) Molecular mechanisms regulating human sperm function. Mol Hum Reprod 3:169-173

28. Gil-Guzman E, Ollero M, Lopez MC, Sharma RK, Alvarez JG, Thomas AJ et al (2001) Differential production of reactive oxygen species by subsets of human spermatozoa at different stages of maturation. Hum Reprod 16:1922-1930

29. Pasqualotto FF, Sharma RK, Nelson DR, Thomas AJ, Agarwal A (2000) Relationship between oxidative stress, semen characteristics, and clinical diagnosis in men undergoing infertility investigation. Fertil Steril 73:459-464

30. Khosravi F, Valojerdi MR, Amanlou M, Karimia L, Abolhassani F (2014) Relationship of seminal reactive nitrogen and oxygen species and total antioxidant capacity with sperm DNA fragmentation in infertile couples with normal and abnormal sperm parameters. Andrologia 46:17-23

31. Shi TY, Chen G, Huang X, Yuan Y, Wu X, Wu B et al (2012) Effects of reactive oxygen species from activated leucocytes on human sperm motility, viability and morphology. Andrologia 44:696-703

32. Nagy A, Polichronopoulos T, Gáspárdy A, Solti L, Cseh S (2015) Correlation between bull fertility and sperm cell velocity parameters generated by computer-assisted semen analysis. Acta Vet Hung 63:370-381

33. Mortimer ST, Mortimer D (1990) Kinematics of human spermatozoa incubated under capacitating conditions. J Androl 11:195-203

34. De Lamirande E, Gagnon C (1993) Human sperm hyperactivation in whole semen and its association with low superoxide scavenging capacity in seminal plasma. Fertil Steril 59:1291-1295

35. Zhou J, Chen L, Li J, Li H, Hong Z, Xie M et al (2015) The semen pH affects sperm motility and capacitation. PloS one. https://doi.org/10. 1371/10e0132974

36. Papac-Milicevic N, Busch CJ, Binder CJ (2016) Malondialdehyde epitopes as targets of immunity and the implications of atherosclerosis. In: Frederick W (ed) Advances in Immunology. Elsevier, London, pp $2-45$

37. Akbari Asbagh F, Mostafavi E, Hamdi K, Azmodeh O, Ghasemynejad A Moshtaghi J (2010) Relation of serum and semen malondialdehyde and total anti-oxidants with sperm parameters in infertile men. Am J Immunol 6:43-49

38. Colagar AH, Karimi F, Jorsaraei SG (2013) Correlation of sperm parameters with semen lipid peroxidation and total antioxidants levels in astheno-and oligoasheno-teratospermic men. Iran Red Crescent Med J 15:780-785

39. Fazeli F, Salimi S (2016) Correlation of seminal plasma total antioxidant capacity and malondialdehyde levels with sperm parameters in men with idiopathic infertility. Avicenna J Med Biochem 4:e29736.
40. Else PL, Kraffe E (1848) Docosahexaenoic and arachidonic acid peroxidation: it's a within molecule cascade. BBA Biomembranes 2015:417-421

41. Malo AF, Garde JJ, Soler AJ, García AJ, Gomendio M, Roldan ER (2005) Male fertility in natural populations of red deer is determined by sperm velocity and the proportion of normal spermatozoa. Biol Reprod 72:822-829

42. Santolaria P, Vicente-Fiel S, Palacín I, Fantova E, Blasco ME, Silvestre MA et al (2015) Predictive capacity of sperm quality parameters and sperm subpopulations on field fertility after artificial insemination in sheep. Anim Reprod Sci 163:82-88

43. Farooq U, Malecki IA, Mahmood M, Martin GB (2017) Appraisal and standardization of curvilinear velocity (VCL) cut-off values for CASA analysis of Japanese quail (Coturnix japonica) sperm. Reprod Domest Anim 52:389-396

44. Khosrowbeygi A, Zarghami N, Deldar Y (2004) Correlation between sperm quality parameters and seminal plasma antioxidants status. Iran J Reprod Med 2:58-64

45. Siciliano L, Tarantino P, Longobardi F, Rago V, Stefano C, Carpino A (2001) Impaired seminal antioxidant capacity in human semen with hyperviscosity or oligoasthenozoospermia. J Androl 22:798-803

46. Tavilani H, Goodarzi MT, Vaisi-Raygani A, Salimi S, Hassanzadeh T (2008) Activity of antioxidant enzymes in seminal plasma and their relationship with lipid peroxidation of spermatozoa. International braz j urol 34:485-491

47. Atig F, Raffa M, Ali HB, Abdelhamid K, Saad A, Ajina M (2012) Altered antioxidant status and increased lipid per-oxidation in seminal plasma of Tunisian infertile men. Int J Biol Sci 8:139-149

48. Murawski M, Saczko J, Marcinkowska A, Chwiłkowska A, Gryboś M, Banaś T (2007) Evaluation of superoxide dismutase activity and its impact on semen quality parameters of infertile men. Folia Histochem Cytobiol 45:123-126

49. Yan L, Liu J, Wu S, Zhang S, Ji G, Gu A (2014) Seminal superoxide dismutase activity and its relationship with semen quality and SOD gene polymorphism. J Assist Reprod Genet 31:549-554

50. Hsieh YY, Sun YL, Chang CC, Lee YS, Tsai HD, Lin CS (2002) Superoxide dismutase activities of spermatozoa and seminal plasma are not correlated with male infertility. J Clin Lab Anal 16:127-131

51. Macanovic B, Vucetic M, Jankovic A, Stancic A, Buzadzic B, Garalejic E et al (2015) Correlation between sperm parameters and protein expression of antioxidative defense enzymes in seminal plasma: a pilot study. Dis Markers 2015:436236.

52. Brahem S, Jellad S, Ibala S, Saad A, Mehdi M (2012) DNA fragmentation status in patients with necrozoospermia. Syst Biol Reprod Med 58:319-323

53. Muratori M, Maggi M, Spinelli S, Filimberti E, Forti G, Baldi E (2003) Spontaneous DNA fragmentation in swim-up selected human spermatozoa during long term incubation. J Androl 24:253-262

54. Samplaski MK, Dimitromanolakis A, Lo K, Grober ED, Mullen B, Garbens A et al (2015) The relationship between sperm viability and DNA fragmentation rates. Reprod Biol Endocrinol 13:42

55. Sakkas D, Mariethoz E, Manicardi G, Bizzaro D, Bianchi PG, Bianchi U (1999) Origin of DNA damage in ejaculated human spermatozoa. Rev Reprod 4:31-37

56. Agarwal A, Tsarev I, Erenpreiss J, Sharma R. Sperm chromatin assessment. In Textbook of Assisted Reproductive Techniques Gardner ed. Weissman, A., Howles, C.M. and Shoham, Z. Taylor \& Francis Group, New York; 2012. 75-95.

57. Wright C, Milne S, Leeson H (2014) Sperm DNA damage caused by oxidative stress: modifiable clinical, lifestyle and nutritional factors in male infertility. Reprod Biomed Online 28:684-703

58. Barroso G, Morshedi M, Oehninger S (2000) Analysis of DNA fragmentation, plasma membrane translocation of phosphatidylserine and oxidative stress in human spermatozoa. Hum Reprod. 15:1338-1344

59. Xia Y, Cheng S, Bian Q, Xu L, Collins MD, Chang HC et al (2004) Genotoxic effects on spermatozoa of carbaryl-exposed workers. J Toxicol Sci. 85:615-623

60. Karydis S, Asimakopoulos B, Papadopoulos N, Vakalopoulos I, AL-Hasani SA, Nikolettos N. (2005) ICSI outcome is not associated with the incidence of spermatozoa with abnormal chromatin condensation. In vivo. 19:921-925 
61. Zini A, Bielecki R, Phang D, Zenzes MT (2001) Correlations between two markers of sperm DNA integrity, DNA denaturation and DNA fragmentation, in fertile and infertile men. Fertil Steril. 75:674-677

62. Sheikh N, Amiri I, Farimani M, Najafi R, Hadeie J (2008) Correlation between sperm parameters and sperm DNA fragmentation in fertile and infertile men. Int J Reprod Biomed (Yazd). 6:13-18

63. Boushaba S, Belaaloui G (2015) Sperm DNA fragmentation and stand ard semen parameters in Algerian infertile male partners. World J Mens Health. 33:1-7
64. Evgeni E, Charalabopoulos K, Asimakopoulos B (2014) Human sperm DNA fragmentation and its correlation with conventional semen parameters. J Reprod Infertil. 15:2-14

\section{Publisher's Note}

Springer Nature remains neutral with regard to jurisdictional claims in published maps and institutional affiliations.

\section{Submit your manuscript to a SpringerOpen ${ }^{\circ}$ journal and benefit from:}

- Convenient online submission

- Rigorous peer review

- Open access: articles freely available online

- High visibility within the field

Retaining the copyright to your article

Submit your next manuscript at $\boldsymbol{\sim}$ springeropen.com 